\title{
Synthetic Peptide (P-21) Derived from Asp-Hemolysin Inhibits the Induction of Apoptosis on HUVECs by Lysophosphatidylcholine
}

\author{
Hiromu Tsutsumi, Takeshi Kumagai,* Saori Naitoo, Keiichi Ebina, and Katsushi Yokota \\ First Department of Hygienic Chemistry, Tohoku Pharmaceutical University; 4-4-1 Komatsushima, Aoba-ku, Sendai, \\ Miyagi 981-8558, Japan. Received January 24, 2006; accepted February 20, 2006; published online February 22, 2006
}

\begin{abstract}
Lysophosphatidylcholine (LPC), formed during low-density lipoprotein (LDL) oxidation and located within atherosclerotic plaques, regulates a variety of cellular functions, some of which could be construed to promote atherosclerotic lesion development, including vascular muscle cell proliferation, monocyte attraction, and endothelial cell apoptosis. We have previously reported that the synthetic peptide derived from Asp-hemolysin, named P-21, inhibits oxidized LDL (OxLDL)-induced macrophage proliferation through binding of P-21 to OxLDL. In this study, to clarify the interaction between P-21 and LPC as a typical lipid moiety of OxLDL, we examined the influence of P-21 on LPC-induced apoptosis in human umbilical vein endothelial cells (HUVECs). Based on flow cytometric analysis, using annexine $\mathrm{V}$-fluorescein isothiocianate and propidium iodide as probes to assess apoptosis, LPC induced the apoptosis of HUVECs, and P-21 significantly inhibited this activity by $82.4 \%$. Furthermore, dissociation-enhanced lanthanide fluorometric immunoassay indicated that LPC inhibited the binding of P-21 to OxLDL in a dose-dependent manner. A $50 \%$ inhibition dose was estimated to be $4.65 \mu \mathrm{M}$ of LPC. These results suggest that P-21 inhibits LPC-induced HUVEC apoptosis through binding of P-21 to LPC.
\end{abstract}

Key words Asp-hemolysin-related peptide; lysophosphatidylcholine; apoptosis; binding

It has been firmly established that elevated plasma concentrations of low-density lipoprotein (LDL) are associated with accelerated atherogenesis, and clinical trials demonstrate that LDL-lowering treatments reduce the risk of death in patients with coronary artery disease. ${ }^{1)}$ Recent evidence suggests that the oxidative modification of LDL renders it more atherogenic $^{2)}$ and oxidized LDL (OxLDL) has been identified in atherosclerotic lesions. ${ }^{3)}$ OxLDL and its lipid constituents have numerous detrimental effects on endothelial cell function, ${ }^{4)}$ including the induction of apoptosis. ${ }^{5)}$ An active component of OxLDL is lysophosphatidylcholine (LPC), which is generated during LDL oxidation through the enzymatic hydrolysis of phosphatidylcholine by the platelet-activating factor acetylhydrolase (PAF-AH), an enzyme normally associated with LDL. $\left.{ }^{6}\right)$ Recently, Sata et al. demonstrated that OxLDL or LPC induces endothelial cell apoptosis by sensitizing endothelial cells to Fas-mediated apoptosis. ${ }^{7)}$ Apoptosis is increasingly observed as plaques develop, although the exact mechanisms and consequences of apoptosis in the development and progression of atherosclerosis are still controversial.

Asp-hemolysin is a hemolytic toxin from Aspergillus fumigatus. ${ }^{8)}$ The gene for Asp-hemolysin has been cloned and the gene sequence has been reported. ${ }^{9)}$ The sequence of the primary Asp-hemolysin gene product, predicted from the cDNA sequence, consists of 131 amino acid residues and has a molecular mass of 14275 . We have previously reported that Asp-hemolysin is a specific binding protein for OxLDL with high affinity $\left(K_{\mathrm{D}}=0.63 \mu \mathrm{g} / \mathrm{ml}\right)$, and its binding specificity is distinct from any receptor for OxLDL. ${ }^{10)}$ In addition, we have reported that LPC as a typical lipid moiety of OxLDL is involved in the binding of Asp-hemolysin to OxLDL, and that Asp-hemolysin is a binding protein for LPC. ${ }^{11)}$ Recently, Kumagai et al. demonstrated that the synthetic peptide derived from Asp-hemolysin, named P-21, inhibits OxLDL-induced macrophage proliferation through binding of P-21 to OxLDL. ${ }^{12)}$
In this paper, to clarify the interaction between P-21 and LPC as a major active component of OxLDL, we investigated the effect of P-21 on LPC-induced human umbilical vein endothelial cells (HUVECs) apoptosis. Our results suggest that P-21 inhibits LPC-induced HUVECs apoptosis through binding of P-21 to LPC.

\section{MATERIALS AND METHODS}

Synthetic Peptide The peptide corresponding to $21-41$ of Asp-hemolysin amino acid sequence ${ }^{9}$ (IKNASLSWGKWYKDGDKDAEI, P-21) and N-terminally biotinylated P-21 were synthesized by Bio Synthesis Inc. (Lewisville, Texas, U.S.A.). These peptides were purified by reverse HPLC and subsequently analyzed by laser desorption mass spectrometry.

Reagent The LPC used was 1-palmitoyl-sn-glycero-3phosphocholine from Sigma (St. Louis, MO, U.S.A.), which was freshly dissolved in ethanol at $10 \mathrm{~mm}$.

Cell Culture HUVECs were purchased from Clonetics (San Diego, CA, U.S.A.). HUVECs were cultured in EGM-2 medium (Clonetics) containing 2\% FBS, $0.04 \%$ hydrocortisone, $0.1 \%$ human EGF, $0.4 \%$ human FGF-B, $0.1 \%$ VEGF, $0.1 \%$ ascorbic acid, $0.1 \% \mathrm{R}^{3}-\mathrm{IGF}-1,0.1 \%$ heparin, and $0.1 \%$ GA- 1000 at $37^{\circ} \mathrm{C}$ in a humidified $5 \% \mathrm{CO}_{2}$ incubator. At confluence, cells were trypsinized, counted and adjusted to $3 \times 10^{5}$ cells $/ \mathrm{ml}$ for cell viability assay and flow cytometric analysis. For cell viability assay, $0.1 \mathrm{ml}$ of cell suspension was added per 96-well tissue culture plate. For flow cytometric analysis, $1 \mathrm{ml}$ of cell suspension was added per $35 \mathrm{~mm}$ culture dish. In all experiments, HUVECs were used from the second to fifth passages.

Preparation and Oxidation of LDL Human LDL $(d=1.019-1.063)$ was isolated by sequential ultracentrifugation from fresh plasma collected in EDTA $(1 \mathrm{mg} / \mathrm{ml})$ as previously described. ${ }^{13)}$ The protein content of the LDL was assayed using the method of Lowry et al. with bovine serum albumin as the standard. ${ }^{14)}$ LDL was oxidized in the presence 
of $5 \mu \mathrm{M} \mathrm{CuSO}$ for $4 \mathrm{~h}$ at $37^{\circ} \mathrm{C}$. The extent of oxidation was assessed by measuring the thiobarbituric acid reactive substances (TBARS) ${ }^{15}$ and relative electrophoretic mobility (REM) in $1 \%$ agarose gel compared with native LDL. The TBARS content of OxLDL was 86.39 \pm 12.19 (mean \pm S.D.) nmol malomdialdehyde/mg protein. The REM value of the OxLDL preparation was 1.8 .

Flow Cytometry Apoptosis was detected using an MEBCYTO $^{\circledR}$ Apoptosis Kit (MBL). HUVECs were incubated to LPC $(0-75 \mu \mathrm{M})$ in the absence or presence of P-21 $(100 \mu \mathrm{g} / \mathrm{ml})$ for $2 \mathrm{~h}$. The cells were collected and washed with phosphate-buffered saline (PBS). To prepare the cell sample for flow cytometry, cells were resuspended in binding buffer and washed twice with PBS. The cells were resuspended in binding buffer and stained with annexine V-fluorescein isothiocyanate (FITC) and propidium iodide (PI) for $15 \mathrm{~min}$ at room temperature in the dark. The cell samples were analyzed by FACS flow cytometer using CELL QUEST software (Becton Dickinson, Mountain View, CA, U.S.A.).

Cell Viability Assay LPC $(0-45 \mu \mathrm{M})$ was preincubated with P-21 $(100 \mu \mathrm{g} / \mathrm{ml})$ for $30 \mathrm{~min}$ at $37^{\circ} \mathrm{C}$. HUVECs were cultured with LPC or a preincubation mixture of LPC and P21 for $2 \mathrm{~h}$. Cell viability was determined by the WST-8 [2-(2methoxy-4-nitropheyl)-3-(4-nitrophenyl)-5-(2,4-dinitrophenyl)-2 $H$-tetrazolium, monosodium salt] assay using a Cell Counting Kit-8 (Dojindo). Briefly, $10 \mu \mathrm{l}$ of WST-8/1methoxy-phenazine methosulfate solution was added to each well of a 96-well plate and incubated for $2 \mathrm{~h}$ at $37^{\circ} \mathrm{C}$. Absorbance at $450 \mathrm{~nm}$ was then measured with a multiwell spectrophotometer.

Dissociation-Enhanced Lanthanide Fluorometric Immunoassay (DELFIA) The effect of LPC on P-21 binding to OxLDL by DELFIA was measured utilizing lanthanide chelates and time-resolved fluorometry. ${ }^{16)} \mathrm{LPC}(10 \mu \mathrm{M})$ was preincubated with biotinylated P-21 $(2.5 \mu \mathrm{g} / \mathrm{ml})$ for $15 \mathrm{~min}$ at $37^{\circ} \mathrm{C}$. Rabbit anti-human $\beta$-lipoprotein IgG fractions $(1 \mu \mathrm{g} /$ $100 \mu$, Nippon Biotest Labo.) were placed in a 96-well microtiter plate and incubated overnight at $4{ }^{\circ} \mathrm{C}$. After removing the antibody fluid, the wells were blocked with SuperBlock ${ }^{\circledR}$ Blocking Buffer in PBS (Pierce). After washing the well three times with $\mathrm{PBS}, 10 \mu \mathrm{g} / \mathrm{ml}$ of $\mathrm{OxLDL}$ was added to each well. After incubation for $1 \mathrm{~h}$ at $37^{\circ} \mathrm{C}$, the plates were washed with PBS. Then, $100 \mu \mathrm{l}$ of $2.5 \mu \mathrm{g} / \mathrm{ml}$ biotinylated P-21 or $100 \mu \mathrm{l}$ of preincubation mixture of LPC and biotinylated P-21 were added to each well and incubated for $30 \mathrm{~min}$ at $37^{\circ} \mathrm{C}$, followed by $100 \mu \mathrm{l}$ of $\mathrm{Eu}^{3+}$-labelled streptavidine (Wallac Oy) (1:1000 diluted in PBS) for $30 \mathrm{~min}$ at room temperature. After washing the well six times with PBS, $100 \mu \mathrm{l}$ of DELFIA enhancement solution (Wallac Oy) was added to each well. After shaking for $5 \mathrm{~min}$, we determined the fluorescence using a 1420 ARVOsx DELFIA Research Fluorometer (Wallac Oy) at the standard setting for $\mathrm{Eu}^{3+}$ (excitation wavelength of $340 \mathrm{~nm}$ and an emission wavelength of $615 \mathrm{~nm})$.

Statistical Analysis Data were evaluated by paired Student's $t$-test. When the $p$ value was less than 0.05 , the difference was considered significant.

\section{RESULTS}

Effect of P-21 on the LPC-Induced Apoptosis of $\mathrm{HU}$ -
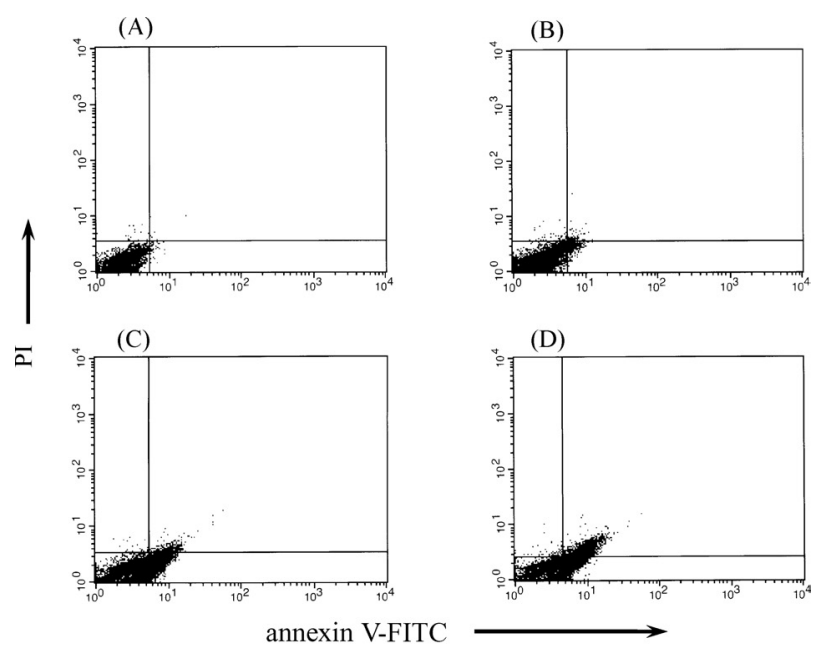

(E)

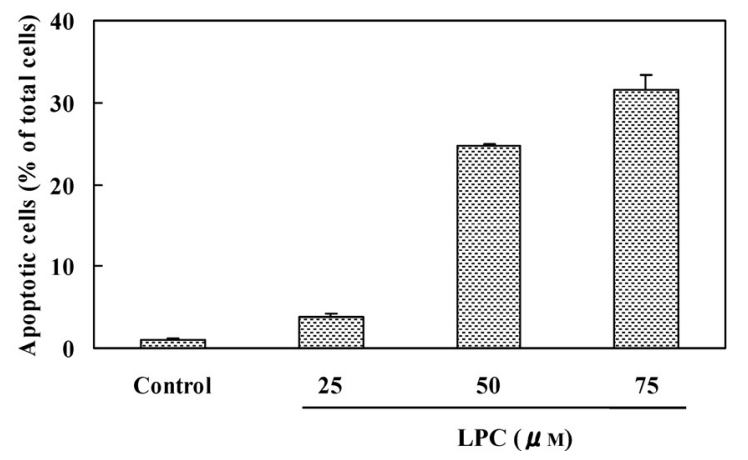

Fig. 1. Induction of Apoptosis by LPC in HUVECs

HUVECs were incubated with LPC for $2 \mathrm{~h}$ and various concentrations of LPC as shown below. PS externalization and PI incorporation were detected using the MEBCYTO $^{\circledR}$ apoptosis kit with FACScan. (A) Control cells. (B) Cells treated with $25 \mu \mathrm{M}$ of LPC. (C) Cells treated with $50 \mu \mathrm{M}$ of LPC. (D) Cells treated with $75 \mu \mathrm{M}$ of LPC. (E) Percentage of apoptosis in (A) - (D) calculated using CELL QUEST software. Results represent the mean \pm S.D. of three separate experiments.

VECs To examine the induction of apoptosis in HUVECs by LPC, HUVECs were treated with various concentrations of LPC for $2 \mathrm{~h}$. As shown in Fig. 1, LPC caused apoptosis in HUVECs at 3.9, 24.6 and $31.6 \%$ when HUVECs were treated with 25,50 and $75 \mu \mathrm{M}$ of LPC, respectively. However, at the highest concentration $(75 \mu \mathrm{M})$ employed, the necrotic cell population increased from the baseline to $21.6 \%$. In addition, apoptosis determined by phosphatidylserine exposure was confirmed by the DNA fragmentation ladder pattern (data not shown). We next examined the effect of P-21 on LPC-induced apoptosis of HUVECs. When HUVECs were incubated with $50 \mu \mathrm{M}$ of LPC in the presence or absence of $100 \mu \mathrm{g} / \mathrm{ml}$ of P-21, LPC-induced apoptosis in HUVECs was significantly inhibited by $82.4 \%$ with P-21 (Fig. 2). Furthermore, we also examined the effect of P-21 on LPC-induced apoptosis of HUVECs by WST- 8 assay as a parameter of apoptosis detection. HUVECs were treated with different doses of LPC in the presence or absence of P-21 for $2 \mathrm{~h}$. As shown in Fig. 3, LPC decreased the cell viability of HUVECs by 101.1, 67.7, 26.6 and 7.2\% when HUVECs were treated with $25,35,40$ and $45 \mu \mathrm{M}$ of LPC, respectively. On the other hand, P-21 treatment almost completely inhibited the decreased cell viability of HUVECs induced by LPC. In contrast, P-21 alone did not affect HUVEC apoptosis (data not shown). 

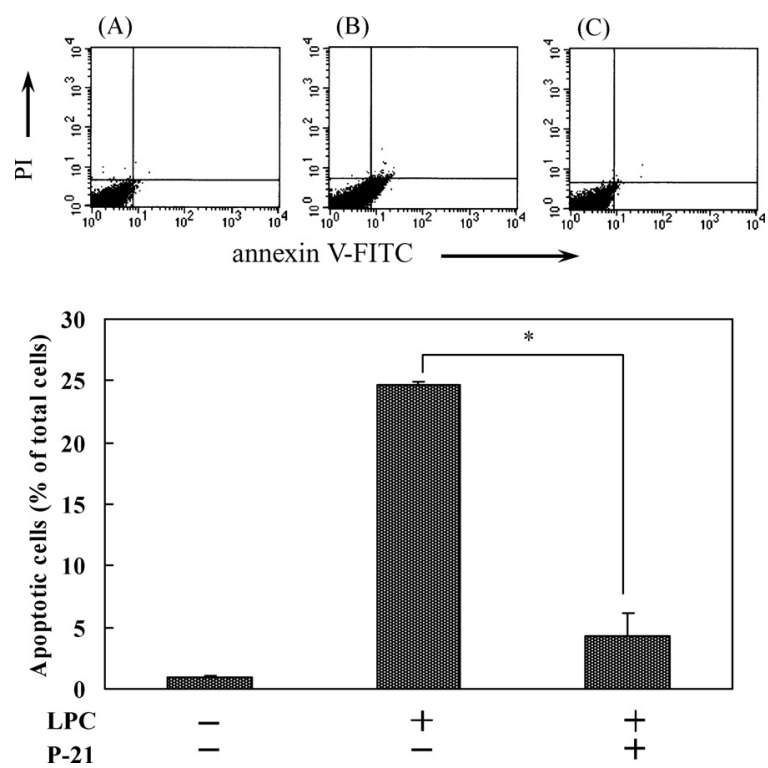

Fig. 2. Effect of P-21 on LPC-Induced Apoptosis in HUVECs

HUVECs were incubated with LPC $(50 \mu \mathrm{M})$ in the absence or presence of P-21 $(100 \mu \mathrm{g} / \mathrm{ml})$ for $2 \mathrm{~h}$. (A-C) The apoptotic cell population was assessed using the MEBCYTO $^{\circledR}$ apoptosis detection kit with FACScan. (D) Percentage of apoptosis in (A) - (C) calculated using CELL QUEST software. Results represent the mean \pm S.D. of three separate experiments. $* p<0.005$, compared with LPC alone.

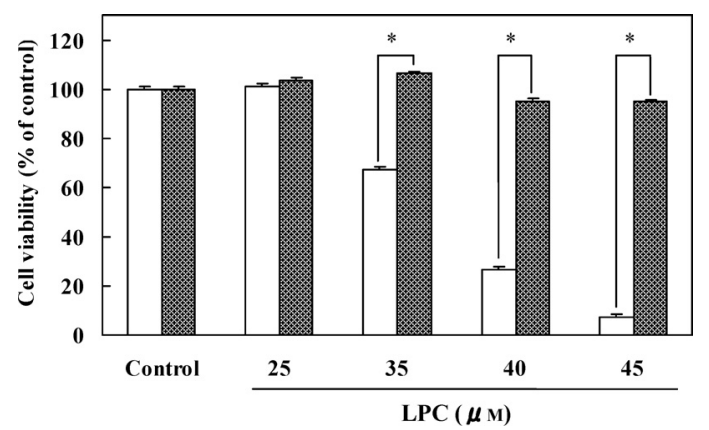

Fig. 3. Effect of P-21 on Various Concentrations of LPC-Induced Apoptosis

HUVECs were cultured with $25,35,40$ and $45 \mu \mathrm{M}$ of LPC in the absence (open column) or presence (closed column) of P-21 $(100 \mu \mathrm{g} / \mathrm{ml})$ for $2 \mathrm{~h}$. The cell viability of HUVECs was measured by WST- 8 assay. Results represent the mean \pm S.D. of three separate experiments. $* p<0.05$, compared with LPC alone.

Effect of LPC on P-21 Binding to OxLDL To clarify the interaction between P-21 and LPC, we examined the effect of LPC on the binding of P-21 to OxLDL by DELFIA using biotinylated P-21. OxLDL was added to microtiter wells procoated with rabbit anti-human $\beta$-lipoprotein antibody and then a premixture of biotinylated P-21 and LPC was added to each well. After washing, the amount of OxLDL-biotinylated P-21 complex remaining in the wells was determined using $\mathrm{Eu}^{3+}$-labelled streptavidine. As shown in Fig. 4, the incubation of biotinylated P-21 to OxLDL significantly increased the fluorescence intensity. On the other hand, LPC inhibited the binding of P-21 to OxLDL by 18.6, $43.2,62.2$ and $78.7 \%$ when compared to the control with a LPC concentration of 2, 4, 6 and $8 \mu \mathrm{M}$, respectively. The $50 \%$ inhibition dose was estimated to be $4.65 \mu \mathrm{m}$ of LPC.

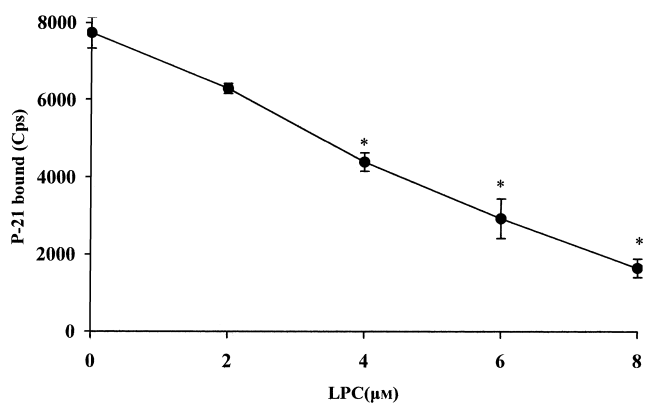

Fig. 4. Effect of LPC on P-21 Binding to OxLDL

OxLDL was added to microtiter wells precoated with rabbit anti-human $\beta$-lipoprotein antibody, and then the reaction mixture of biotinylated P-21 and LPC was added to each well. DELFIA was carried out with $\mathrm{Eu}^{3+}$-labelled streptavidin. Results represent the mean \pm S.D. of three separate experiments. $* p<0.01$, compared with the control.

\section{DISCUSSION}

It has been shown that when LDL is oxidized to OxLDL, its phospholipid moiety PC is converted to LPC, which is present in OxLDL. ${ }^{17)}$ It has been speculated that the oxidation of LDL to OxLDL in the subendothelium is involved in the initiation of atherosclerosis because of its recruitment of monocytes and $\mathrm{T}$ lymphocytes into the subendothelial space. LPC has many effects that are expected to play important roles in atherogenesis. ${ }^{18)}$ For example, LPC stimulates cytokine, ${ }^{19)}$ adhesion molecules ${ }^{20)}$ growth factor population, ${ }^{21)}$ and apoptosis induction. ${ }^{22)}$ Many studies have identified that cell apoptosis increased in atherosclerotic plaques compared with normal vascular vessels. ${ }^{23)}$ In addition, Phoebe et al. reported that LPC-promoted apoptosis through G2A provides the first account of LPC causing apoptosis through a distinct G protein-coupled receptor-mediated mechanism. ${ }^{24}$ Moreover, it is known that oxysterol and oxidized phospholipids including OxLDL also induced apoptosis in HUVECs. ${ }^{25)}$ In this study, we demonstrated that P-21, a synthetic peptide derived from a region of Asp-hemolysin rich in positive charges, significantly inhibited LPC-induced apoptosis in HUVECs (Fig. 2). In addition, the WST-8 assay also showed that P-21 inhibited LPC-induced apoptosis in a dose-dependent manner (Fig. 3). Furthermore, we indicated that LPC inhibited the binding of P-21 to OxLDL in a dose-dependent manner (Fig. 4). These results suggest that P-21 inhibits LPC-induced apoptosis in HUVECs through binding of P-21 to LPC. However, the effect of P-21 on oxysterol or oxidized phospholipids induced HUVECs apoptosis has not clarified in detail. Futher studies are needed to elucidate the issue.

Endothelial cell apoptosis represents a critical event for the initiation of atherosclerosis. ${ }^{26)}$ The concept of an association between endothelial cell apoptosis and the development of atherosclerosis has been supported by the hypothesis that disturbed shear stress on the vessel wall or adhesive platelets participates in endothelial cell apoptosis. Recent direct evidence demonstrated that endothelial cell apoptosis increases in the downstream part of atherosclerotic plaques whereas blood flow-mediated shear stress is low. ${ }^{27)}$ These findings show that endothelial cell apoptosis is involved in determining the susceptibility to atherosclerotic lesion development. Thus, our results indicate that P-21 may be a useful as a new diagnostic and therapeutic tool for atherosclerosis.

In conclusion, we have shown that P-21, an Asp-he- 
molysin-related peptide, inhibits LPC-induced HUVEC apoptosis, and its mechanism may be dependent on the binding of P-21 to LPC. Further study on the binding mechanism between Asp-hemolysin-related peptide and LPC may provide important information on the prevention and treatment of atherosclerosis.

\section{REFERENCES}

1) Scandinavian Simvastatin Survival Study Group, Lancet, 344, 13831389 (1994).

2) Steinberg D., J. Biol. Chem., 272, 20936-20966 (1997).

3) Yla-Herttualä S., Palinski W., Rosenfeld M. E., Parthasarathy S., Carew T. E., Butler S. W., Witztum J. L., Steinberg D., J. Clin. Invest., 84, 1086-1095 (1989).

4) Kugiyama K., Kerns S. A., Morrisett J. D., Roberts R., Henry P. D., Nature (London), 344, 215-218 (1990).

5) Escargueli-Blanc I., Meilhac O., Pieraggi M.-T., Arnal J.-F., Salvayre R., Negre-Salvayre A., Arterioscler. Thromb. Vasc. Biol., 17, 331-339 (1997).

6) Steinbrecher U. P., Parthasarathy S., Leake D. S., Witztum J. L., Steinberg D., Proc. Natl. Acad. Sci. U.S.A., 81, 3883-3887 (1984).

7) Sata M., Walsh K., J. Biol. Chem., 273, 33103-33106 (1998).

8) Yokota K., Shimada H., Kamaguchi A., Sakaguchi O., Microbiol. Immunol., 21, $11-22$ (1977).

9) Ebina K., Sakagami H., Yokota K., Kondo H., Biochim. Biophys. Acta, 1219, 148-150 (1994).

10) Kudo Y., Fukuchi Y., Kumagai T., Ebina K., Yokota K., Biochim. Bio- phys. Acta, 1568, 183-188 (2001).

11) Kudo Y., Ootani T., Kumagai T., Fukuchi Y., Ebina K., Yokota K., Biol. Pharm. Bull., 25, 787-790 (2002).

12) Kumagai T., Ogawa N., Tsutsumi H., Ebina K., Yokota K., Biol. Pharm. Bull., 28, 1381-1384 (2005).

13) Havel R. J., Eder H. A., Bragdon J. H., J. Clin. Invest., 34, 1345-1353 (1995).

14) Lowry O. H., Rosebrough N. J., Farr A. L., Randall R. J., J. Biol. Chem., 193, 265-275 (1951).

15) Yagi K., Biochem. Med., 15, 212-216 (1976).

16) Soini E., Kojila H., Clin. Chem., 29, 65-68 (1983).

17) Kusuhara M., Chait A., Cader A., Berk B. C., Arterioscler. Thromb. Vasc. Biol., 17, 141-148 (1997).

18) Berliner J. A., Heinecke J. W., Free Radic. Biol. Med., 20, 707-727 (1996).

19) Nishi E., Kume N., Ueno Y., Ochi H., Morikawa H., Kita T., Circ. Res., 83, 508-515 (1998).

20) Ochi H., Kume N., Nishi E., Morikawa H., Masuda M., Fujikawa K., Kita T., Biochem. Biophys. Res. Commun., 243, 862-868 (1998).

21) Kume N., Gimbrone M. A. Jr., J. Clin. Invest., 93, 907-911 (1994).

22) Chien-Cheng H., Mao-Hsiung Y., Hwan-Wun L., Ying-Tung L., Atherosclerosis, 151, 481-491 (2000).

23) Geng Y. J., Libby P., Am. J. Pathol., 147, 251-266 (1995).

24) Phoebe L., Richard D. Y., J. Biol. Chem., 278, 14379-14386 (2002).

25) Salvayre R., Auge N., Benoist H., Negre-Salvayre A., Biochim. Biophys. Acta, 1585, 213-221 (2002).

26) Ross R., N. Engl. J. Med., 340, 115-126 (1999).

27) Tricot O., Mallat Z., Heymes C., Belmin J., Leaseche G., Tedgui A., Circulation, 101, 2450-2453 (2000). 